Session 2004-1819

\title{
The Manufacturing Learning Model - An Innovative Method for Manufacturing Education
}

\author{
Winston F. Erevelles - Robert Morris University \\ Pearley Cunningham - Community College of Allegheny County \\ Sunday Faseyitan - Butler County Community College \\ Robert Myers - Westmoreland County Community College
}

\section{Introduction}

The Partnership for Regional Innovation in Manufacturing Education (PRIME) is an industrydriven, academic system delivering innovative manufacturing education and career development in southwestern Pennsylvania. The coalition brings together Robert Morris University (RMU), the Community College of Allegheny County (CCAC), Butler County Community College (BCCC) and Westmoreland County Community College (WCCC) along with dozens of manufacturing partners. PRIME was created in response to the human capital needs of regional manufacturers - i.e. the development of highly skilled technicians and engineers for the manufacturing workforce of tomorrow.

This is done through a comprehensive strategy that currently targets southwestern Pennsylvania. The manufacturing base in this region continues to be the key to a healthy regional economy. Manufacturing is the second largest private sector employer with 160,000 jobs, and first in annual wages with a total payroll of over $\$ 6$ billion $^{1,2}$. The average manufacturing wage of $\$ 40,000$ compares very favorably to the $\$ 28,000$ average of other sectors. In southwestern Pennsylvania, the manufacturing workforce (which is $15 \%$ of the total workforce) accounts for $\$ 56$ billion of a $\$ 139$ billion economy. This is a clear indication of the impact that the relatively small number of manufacturing jobs has on the regional economy.

In order to maintain and grow this base, PRIME operates at various levels. In addition to launching new programs with attendant curricula and facilities, PRIME also offers extensive outreach to middle and high school students and their academic and family communities. PRIME also works to develop and implement innovative methods to disseminate its educational materials and facilitate communication and distance learning amongst its constituencies.

PRIME currently offers five manufacturing technology (two-year) and engineering (four-year) degree programs. The three community colleges partners each offer A.S. degree programs in Manufacturing Technology while Robert Morris University offers the B.S. in Manufacturing Engineering degree. In addition, CCAC offers a three-year bridge program that allows graduates 
to enter the RMU engineering program as juniors. All programs were developed in close partnership with industry and are designed to meet accreditation standards.

The National Science Foundation awarded PRIME a three-year Advanced Technological Education (ATE) grant (Division of Undergraduate Education - DUE \# 0101637) towards the implementation of a comprehensive approach to manufacturing education. The goal of the ATE project is to support the implementation of an industry-driven regional network for manufacturing education at different levels, at times and locations best suited to new and incumbent technicians and engineers. Highlights of the ATE project include:

- The implementation of an active learning model consisting of Exploration, Dialog, and Application steps for engineering technology and engineering students.

- The creation of a web-based conferencing system to network the five campuses and industry partners in order to enhance the learning process and facilitate collaborative learning.

- The closure of the competency gaps identified by regional employers in new hires including technical and professional skills in manufacturing.

- The creation of 20 learning modules in five areas of study - Engineering Materials, Manufacturing Processes, Quality and Metrology, Computer Applications in Manufacturing, and Programmable Logic Controllers with projects from industry partners.

- The implementation of materials common to both two- and four-year institutions.

- The creation of a flexible, user-friendly, and supportive delivery system.

The resources provided by the National Science Foundation served as a catalyst for the curriculum development initiative that was first envisioned when the coalition was formed. This is now addressed in greater detail.

\section{Curriculum development across the PRIME coalition}

Three drivers characterize the manufacturing programs offered by the academic partners of PRIME. Firstly, a program at a given institution must address the needs of its industrial constituencies and close manufacturing competency gaps specific to that cohort. Secondly, programs must strive to maintain content that would be compatible with accreditation requirements. Finally, the degree programs across the coalition must be designed so that students may articulate from the A.S. in Manufacturing Technology or the three-year bridge program into the B.S. in Manufacturing Engineering.

This philosophy meant that each institution would have a slightly different "flavor". At the A.S. in Manufacturing Technology level for example, the program at BCCC focuses on tool \& die technology and metrology while the one at CCAC focuses on materials and controls. In comparison, the program at WCCC features a common first year in the technology program and offers specialization in the areas of manufacturing processes, electronics manufacturing, manufacturing maintenance, and chemical process technologies during the second year in the program. Each of these programs is to be accredited by NAIT. The RMU program addresses the four major areas required by SME and EAC/ABET: materials and processes; product, tool, and assembly; manufacturing systems; and manufacturing competitiveness. 
There however remained a pressing need to establish a curricular framework that was (a)modular in nature, (b)consistent in its pedagogical approach and (c)had a common look and feel. This is significant for several reasons. Students articulating from a technology program to an engineering program would already be familiar with the methodology. A non-traditional student taking courses at multiple academic sites would be more productive. This approach would allow the coalition to market a suite of educational modules and course to regional industry under a unified umbrella. Finally, the breakdown into a modular structure is essential in that courses are different institutions do not necessarily conform to a single model and modularity is desirable.

Development of this framework was achieved by comparing the curricular needs at each institution in light of industry needs, accreditation requirements, and articulation plans. The results of these deliberations appear in Table I, which shows areas where the institutions have common courseware needs.

Table I. Curricular Emphases of PRIME at the Partner Institutions

\begin{tabular}{|l|l|l|l|l|}
\hline & $\begin{array}{l}\text { Materials, } \\
\text { Processes, and } \\
\text { Methods in } \\
\text { Manufacturing }\end{array}$ & $\begin{array}{l}\text { Product, Tools, and } \\
\text { Fixture Design }\end{array}$ & $\begin{array}{l}\text { Metrology \& } \\
\text { Quality/ } \\
\text { Instrumentation \& } \\
\text { Measurement }\end{array}$ & $\begin{array}{l}\text { Automation, } \\
\text { Controls, and } \\
\text { Manufacturing } \\
\text { Systems }\end{array}$ \\
\hline RMU & $\bullet$ & $\bullet$ & $\bullet$ & $\bullet$ \\
\hline CCAC & $\bullet$ & $\bullet$ & $\bullet$ & $\bullet$ \\
\hline BCCC & $\bullet$ & $\bullet$ & $\bullet$ & $\bullet$ \\
\hline WCCC & & $\bullet$ & $\bullet$ & $\bullet$ \\
\hline
\end{tabular}

For the first phase, the PRIME partners decided to address the following five areas of common need that would build on basic scientific and mathematical principles and skills:

- Engineering Materials

- Manufacturing Processes

- Measurement \& Quality

- Computers Applications in Manufacturing

- Programmable Logic Controllers

For each of these five areas, a series of four modules is being developed. Each module will represent about a month of activity for a typical college/university course. The modular approach to curriculum development allows materials developed to be deployed over a broad range of academic levels and distributed across multiple courses. PRIME materials will be usable at the Industrial Technology, Engineering Technology and Engineering topics levels of manufacturing education. Dr. Cunningham, a Co-PI in this project, has experience with this type of modular development through his involvement with the Introductory College Physics for the 21st Century Project (DUE \# 9553665). A similar curriculum model is being proposed for application to manufacturing education. With the establishment of a common framework and selection of areas and modules, the next priority was to ensure that these materials would focus on student learning rather than teaching. Further, the pedagogy also called for the integration of theoretical and experiential learning, the incorporation of materials, examples, and problems from industry, and the transition of teaching faculty from their roles as instructors to new roles as coaches. This pedagogical approach is now presented. 


\section{The Manufacturing Learning Model (MLM)}

Research into adult learning has shown that having relevant hands-on activities is critical to student learning. Knowles has stated that for adult learning to be effective it must ${ }^{3}$ :

1. Be relevant to employment or job requirements.

2. Have immediate possible application.

3. Provide actual hands-on exercises.

In addition, recent work in the physical sciences suggests that effective learning is accomplished when students are allowed to build and discover their knowledge in an interactive or active learning environment ${ }^{4,5}$. PRIME has analyzed several initiatives funded by the National Science Foundation in order to implement the best practices from other projects and areas into an active learning environment. This process of integrating the pedagogical approaches from other projects has provided PRIME with insights from other funded initiatives in manufacturing, technical, and science education. These insights have led to the development of the three-step Manufacturing Learning Model that has been systematically applied to the 20 modules that are being developed in the five areas cited earlier.

Each module begins with an industrial situation that must be resolved or understood. 550 companies in southwestern Pennsylvania have been contacted - to date 40 companies have provided the PRIME team access to their facilities to interview, photograph, and videotape their operations. This has provided the development group with industrial problems and examples. Each section of a given module then moves the student toward both an understanding of the concepts and technology important to the situation and to a solution to the problem. Subject experts at the PRIME schools write the modules. Monthly coalition meetings and co-located personnel working closely with the PRIME Technical Programmer ensure that modules have a consistent style and educational approach. A single cycle of the Manufacturing Learning Model appears in Figure 1.

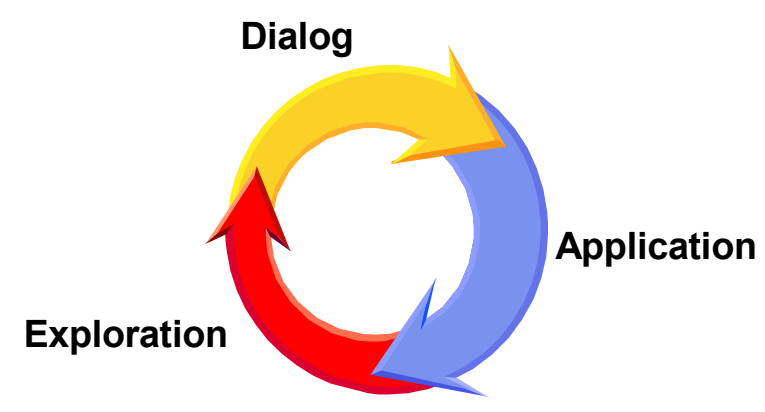

Figure 1. Learning Cycle

1) Exploration Phase - In this portion of a module the students carry out short experiments to demonstrate or discover the basic concepts of the physical phenomena or technology being studied. Students are required to communicate their results in both written and spoken form. 2) Dialog Phase - This portion of the module provides discussion of relevant theory or details of specific techniques that are appropriate to the solution of the problem. Techniques of problem solving, or information presentation are found in this portion of the module.

3) Application Phase - In this portion of the module students are be presented with a problem or series of problems for solution with the ideas and techniques studied. These 
problems may be of a pencil-paper nature or actual hands-on projects/experiments. These problems may be derived from industries that have participated in the development process.

Within a section of the module, the learning cycle is repeated several times in a spiral fashion. Each cycle then develops more deeply the overall concept of the module. Each section ends with a hands-on project experiment. This approach satisfies the three tenets of adult education. By using industry relevant activities, PRIME uses cases, examples and problems that are relevant to job requirements. Secondly, explorations and applications emphasize hands-on activities that are applied immediately to the problem at hand. Finally, the project-based approach gives students a deeper understanding of the module under study through hands-on involvement by the students. Using this model and innovative delivery techniques such as web conferencing, students experience the integration of theory, experimentation, and industry practice in a systematic and iterative manner. Industry partners are deeply involved through the sharing of case studies, video footage, and tours of their facilities and this base is expected to grow.

IV. An example of the MLM at work

The following example has been taken from the Programmable Logic Controller area and has been truncated for purposes of brevity. Figures 2, 3, and 4 illustrate the Exploration, Dialog, and Application phases of the Learning Model.

\section{Exploration: Ladder Diagrams}

The series of circuits below are of simple ladder diagrams of various systems. You should use your PMC system to wire each circuit and test its operation. The charts are provided to summarize the circuit operation. It is common to use the number 1 to represent the switch being closed and the number 0 to indicate the switch being open. Let us further use the convention that if the light is on, record that as a 1 condition and if the light is off record that as a 0 condition. Wire each of the circuits below and fill out the charts.

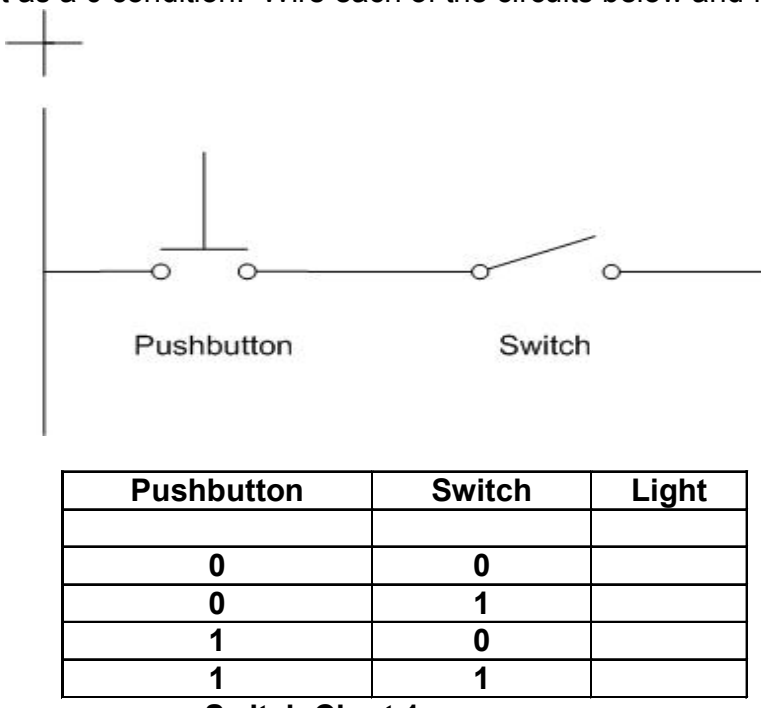

Switch Chart 1

Figure 2. Exploration Example of a Given Cycle 


\section{Dialog: Circuits and Logic}

In control systems the use of logical operations is very common. Each of the circuits above represents a basic logic operation. The logic operations used above are AND, OR, and NOT. Logic operations commonly use the binary number system where the smallest values are either 0 or 1 . These values are called a bit. Many computers use 8 or more bits at a time to code and transfer information. If a system uses 8 bits of data this is referred to as a byte of data. The logic operations operate on only one bit of information at a time, although many devices can do many simultaneous logic operations at once. Each of these logic operations is governed by an operation chart called a truth table. The truth table is an exhaustive list of all possible outcomes for that operation. For example the truth table for the AND operation is shown below.

\begin{tabular}{|c|c|c|}
\hline \multicolumn{3}{|c|}{ AND Truth Table } \\
\hline Switch A & Switch B & Light L \\
\hline 0 & 0 & 0 \\
\hline 0 & 1 & 0 \\
\hline 1 & 0 & 0 \\
\hline 1 & 1 & 1 \\
\hline
\end{tabular}

Figure 3. Dialog Example for that Cycle

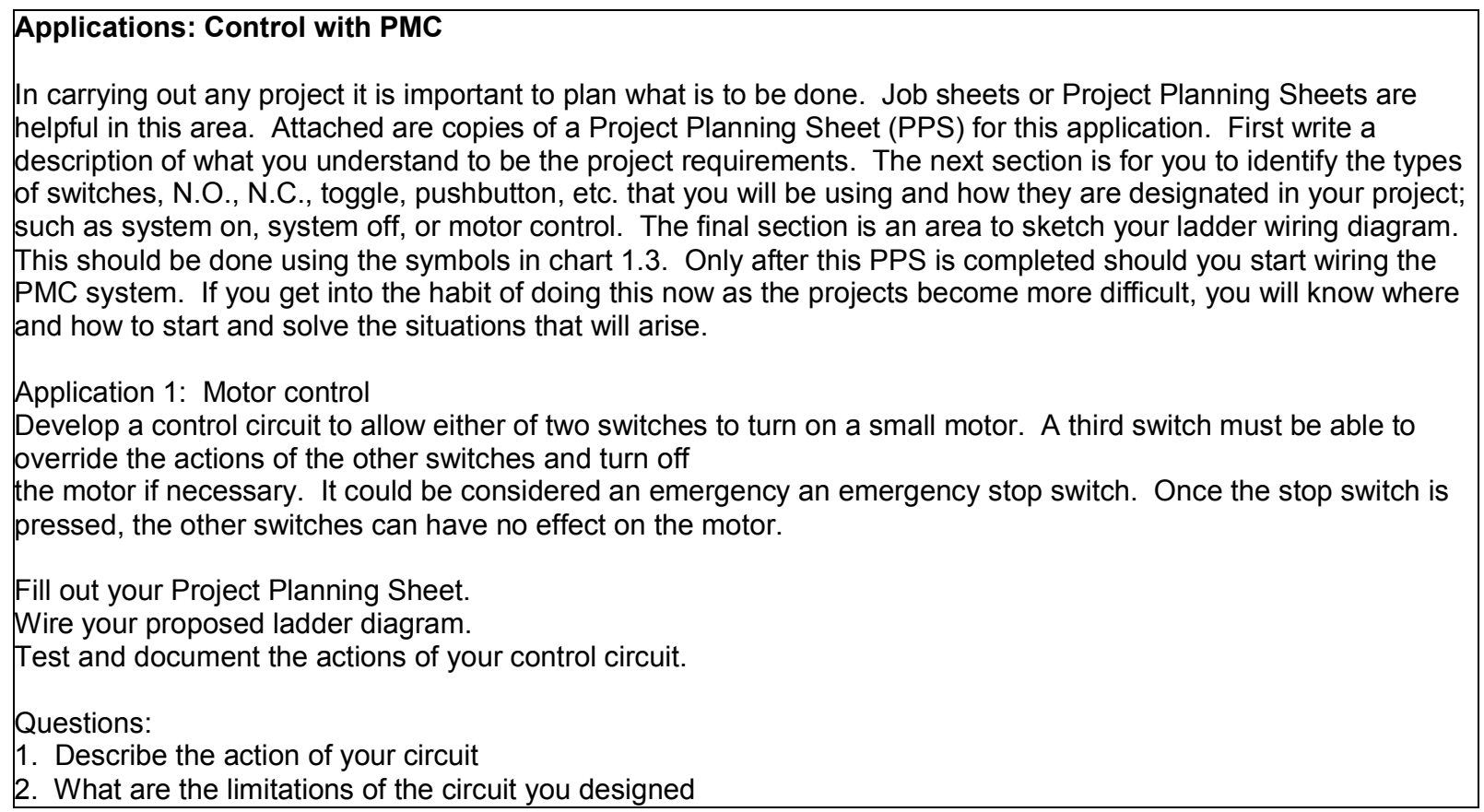
Figure 4. Application Example for the Cycle

Examination of Figure 2 will show that a student begins the cycle by wiring a circuit or using a pre-wired one to explore the fundamentals of logic. Using two switches, the student fills out the state of the output in response to changed states of the input - these are documented in the table. Figure 3 shows the dialog that follows. The instructor at this point would engage the student(s) in a discussion on what just transpired and guide them through the relevant theory - truth tables, normally open and normally closed contacts, and the setting of bits, in this case. With this knowledge gained in experimental and theoretical settings, the student is now ready for an application that appears in Figure 4. In this case s/he is charged with creating a motor control circuit. Instructions that are appropriate for that state are provided and the students are required to answer questions on that application. The application may be supplemented by another 
application or may well serve as the exploration phase for the next cycle. This is an example of a single cycle in one of the modules of one area! These cycles appear repeatedly and in an iterative manner on all 20 modules.

\section{Dissemination and distribution}

All module materials are being developed for delivery in an electronic format. The World Wide Web and a CD-ROM will both be used as the delivery media. A portable document format (pdf) version will be provided for faculty wishing to use the materials with no changes. The original Word documents will be provided to allow faculty to modify or change the materials in response to local needs. Use of the CD-ROM will carry a site license to make as many printed copies as are needed for the course. Faculty wishing to use only a section of the modules need only duplicate that portion. Through a grant from the US Department of Labor, the modules are being converted into an interactive multimedia version using Toolbook software. The PRIME web site will feature a "Faculty Desk" that will contain current information on using the materials, drawings of equipment, equipment lists, vendors, and user comments. All materials are expected to be released starting in the Fall of 2004.

PRIME will hold the copyright on all materials developed by the individual schools. The PRIME partners will be granted full site license to the modules developed under this project. PRIME will be marketing these materials and CD-ROM's and will be exploring various alternatives for the widest possible distribution.

\section{Implementation and assessment}

To date 15 out of 20 modules have been completed with a May 31, 2004 target date for completion of all curricular modules in Word and PDF formats. The conversion to the Toolbook format is expected to be completed by October 2004. In the summer of 2004, "PRIME: Engineering the Future" - the annual conference that provides a forum for the coalition to share its work with academic and industry participants, will be used to extensively showcase the modules that PRIME has completed to date and train participants on using the MLM approach with these modules. At that time the modules will be released for testing to selected conference attendees and participants from the Engineering Technology Division and the Manufacturing Division listserv populations. Editorial and content changes will be made in the Fall of 2004 and the Spring of 2005 - this will be followed by the full release of the 20 modules in Word, PDF, and Toolbook formats. The coalition will provide additional training in the MLM approach and its application during a Spring 2005 seminar that PRIME will host in Pittsburgh.

The work done by PRIME for the NSF project calls for planning, formative, and summative evaluations that are under the oversight of the National Visiting Committee. This group has also evaluated the MLM methodology and the work done to date and has strongly endorsed the work done to date. At each of the sites, the principal investigators and faculty developing the modules have introduced the modules and the method, initially to student interns and then in different classes. The students have received the methodology and materials to date very favorably - the iterative spiral through Exploration, Dialog, and Application have been especially useful in

enhancing student synthesis and application ${ }^{6}$. MLM does represent a paradigm shift for the 
instructor and training is necessary in order to prepare faculty for the different role that this methodology requires. The assessment for the modules themselves is being done used a combination of vehicles such as examinations, project work, and performance on standardized tools such as the Certified Manufacturing Technologist examination. Each of the five areas of development is being mapped against program outcomes as defined by the Engineering Accreditation Commission (EAC) and the Technology Accreditation Commission (TAC) of the Accreditation Board of Engineering and Technology (ABET) and criteria used by the National Association of Industrial Technology ${ }^{7,8}$. Within this matrix, assessment of student performance will be conducted using the Cognitive Domain of Bloom's Taxonomy with the six levels knowledge, comprehension, application, analysis, synthesis, and evaluation, being used to establish a student's learning from basic to mastery levels ${ }^{6}$. The results of the various assessment tools will be used to help in the improvement of the materials and also in the accreditation processes at each partner location.

\section{Conclusions and future work}

The value of the MLM method lies in the integration of theory and practice, the inclusion of real world problems, the ability of a student to work at his/her own pace, the elimination of long lectures disconnected from hands on learning, the ability for these modules to be used anywhere in the curriculum as supplemental learning aids, and the student's ability to use various cycles in touchstone manner - i.e. when a student fails to understand or implement an application within or outside of this environment, s/he can go back to the last successfully completed application and use that as a springboard to understand the material and move forward.

The MLM approach has also impacted the outreach programs sponsored by PRIME. Outreach programs to middle and high school students, school systems, and parents constitute a major operating area for the coalition. Funding from the Alcoa Foundation, the Heinz Endowments, and the US Department of Labor have enabled the coalition to implement a multi-step feeder system called "Molding Minds in Manufacturing". Manufacturing education and career awareness are emphasized through presentations at events such as the National Engineers Week celebrations, the Pittsburgh Sci-Tech Festival, and meetings of professional organizations. PRIME hosts middle and high school students, teachers, and administrators at partner institutions for facility tours and technical presentations. Personnel from PRIME institutions are available for presentations and demonstrations at area schools. Residential and non-residential camps and school year workshops are also part of the menu. PRIME personnel are moving towards the utilization of the Manufacturing Learning Model in outreach programs and have so far trained over a hundred high school teachers in this approach.

The method is expected to significantly impact student learning at the PRIME academic partner campuses and at the sites of industry partners who will use these modules are a training resource. The MLM method is a proven one and PRIME expects to be using it, disseminating the methodology and results, and expanding it to new areas and modules in the future. 
Bibliography

1. PA Department of Labor and Industry, 1994

2. Joseph Zagame, Manufacturing Workforce Clearinghouse, Institute for Economic Transformation, Duquesne University, 1999

3. Knowles, M. S. \& Associates, Androgogy in action, San Francisco, CA: Jossey-Bass, 1984

4. Johnson, S. D. \& Thomas, R. G. "Implications of cognitive science for instructional design in technology education", The Journal of Technical Studies, 20(1), 33-45, (1994 Winter/Spring)

5. Barr, R. \& Tagg, J., "From teaching to learning: A new paradigm for undergraduate education", Change, 13-25. (1995,November, December)

6. Bloom, B.S., "Taxonomy of Educational Objectives, Handbook 1: Cognitive Domain”, Addison-Wesley Pub Co; (January 1984)

7. "Industrial Technology Accreditation Handbook - 2003", http://www.nait.org/

8. “ABET Evaluation Criteria 2004-2005", http://www.abet.org/criteria.html

Winston Erevelles Winston Erevelles is a Professor of Engineering at Robert Morris University and Director of the PRIME coalition. His teaching, research, service, and publishing interests are in the areas of Manufacturing Processes, Automation, Robotics, Rapid Prototyping, Programmable Logic Controllers, and Computer Integrated Manufacturing. He previously served as the Associate Dean of the School of Engineering, Mathematics, and Science and Head of the Learning Factory at the University. He has worked as a Manufacturing Engineer and Plant Manager at Mykron Engineers, India. Dr. Erevelles earned his B.S. in Electrical Engineering from Bangalore University, India and his M.S. and Ph.D. in Engineering Management (Manufacturing Engineering emphasis) from the University of Missouri-Rolla.

Pearley Cunningham is a Department Head and Professor of Engineering Technology and Physics at the Community College of Allegheny County. He also serves as a co-PI for PRIME. He has 28 years of teaching experience in engineering technology, controls, and automation. Dr. Cunningham earned a B.S. degree in Education from Ball State University, an M.S. in Physics from Ohio University, and his Ed.D. from Nova Southeastern University.

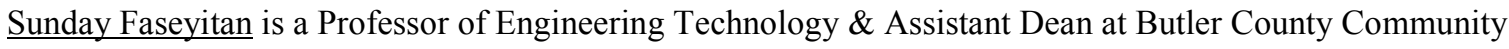
College. He also serves as a co-PI for PRIME. He has 22 years of teaching experience in various areas of design and manufacturing and has also worked in industry for 7 years. Dr. Faseyitan earned a B.S. in Mechanical Engineering from the University of Akron, an M.S. in Industrial Engineering from the University of Pittsburgh, and an Ed.D. in Higher Education Administration from the University of Akron.

Robert Myers is a Professor and Division Chair for Science and Technology at Westmoreland County Community College. He also serves as a co-PI for PRIME. He has 3 years of military experience and has spent the last 30 years in electronics and related areas. Dr. Myers earned a B.S. in Industrial Arts from the California University of Pennsylvania. He earned a Masters of Education, a Vocational Certificate, and his Doctor of Education from the University of Pittsburgh. 